\section{Another gas burst in a Cameroon lake?}

SIR-The emission of gas, mostly $\mathrm{CO}_{2}$, from Lake Nyos on 21 August 1986 that killed about 1,700 people (Freeth, S.J. \& Kay, R.L.F. Nature 325, 104; 1987) drew attention to the large number of crater lakes in Cameroon, many of which have released gas. Since that incident was preceded by a gas burst from Lake Monoum on 15 August 1984, which killed 37 people, it is likely that many of the crater lakes have emitted gas bursts, or will do so.

In February 1987, we sampled sediment cores from the bottom of five lakes, respectively from south to north, Lakes Ossa, Barombi-Mbo, Bambuluwé, Oku and Nyos (Maley, J. et al. J. Volcan. geotherm. Res.; submitted). The measurement of the ${ }^{210} \mathrm{~Pb}$ profile along each core allowed the sedimentation rate over the past century to be determined for three of these lakes, Ossa, Barombi-Mbo and $\mathrm{Oku}$. The natural and artificial radioisotope profiles of the cores from the other two lakes contained certain anomalies (Piboule, M. et al. J. Volcan. geotherm. Res.; submitted).

In the case of Lake Nyos, we concluded that the sediment had been mixed for several metres in depth as there were constant values of ${ }^{137} \mathrm{Cs}$ and ${ }^{210} \mathrm{~Pb}$ along the entire core length. There also appeared to be an excess of ${ }^{210} \mathrm{~Pb}$ due to an additional flux of radon out of the sediment, as shown by a radioactive imbalance be-

\section{Experimental design flaws still unaccounted for}

SIR-For all the space and detailed analysis devoted to the 'Baltimore affair', the issue of the design of the experiments reported by Weaver et al. ${ }^{2}$ has not been raised.

Suppose that in 1985 the possibility arose to pool the resources of two groups. One group had developed reagents that characterize the set of idiotypic determinants expressed in immunoglobulin molecules formed in response to immune challenge with a hapten called NP. The other group had cloned a gene that codes for the completely assembled heavy chain of one of the set of idiotypically indentifiable immunoglobulins formed in response to NP. The gene persisted in several copies in the descendants of at-least two transgenic mice. The value of collaboration between the two groups to study immune regulation would have been evident. And so it must have seemed to the authors of the paper in question.

I assume that all these procedures gave absolutely clearcut results and that any unreported experiments were properly excluded because the experimenters were aware of trivial errors. Thus I ignore all of the issues discussed in ref. 1. tween ${ }^{210} \mathrm{~Pb}$ and ${ }^{226} \mathrm{Ra}$.

In Lake Bambuluwé, located about 10 $\mathrm{km}$ south of Bamenda, the ${ }^{210} \mathrm{~Pb}$ measurements in sediments along the upper $15 \mathrm{~cm}$ exhibit a constant value of radioactivity (369 $\mathrm{Bq} \mathrm{kg}^{-1}$ ). As in Lake Nyos, this activity is unusually strong. We have also observed gas bubbles on the core during its recovery from the bottom of the lake, indicating that its gas content was very close to the gas saturation at the sampling depth (58 $\mathrm{m}$ at Bambuluwé lake).

It therefore appears possible that Lake Bambuluwe is following the same pattern as Lake Nyos, that is an increase of radon flux through the lake sediments. Will this flux, as in Nyos, lead to a large $\mathrm{CO}_{2}$ release? Our present measurements do not allow us to determine this with certainty. As well as completing these first determinations, it will be important to test by a new sampling if modification of the sediment column has taken place since 1987.

Laboratoire de Glaciologie et

M. POURCHET J.F. PINGLOT

Géophysique de l'Environnement, CNRS, Grenoble, France

J. MALEY

Laboratoire de Palynologie, ORSTOM, UR-A3, USTL, Montpellier, France

M.A. Melieres

Laboratoire de Spectrométrie Physique,

USTMG, Grenoble, France

Presumably some hypothesis existed in the minds of the workers. All the collaborators may well have had different hypotheses. But some underlying question beyond the mindless "let us see what happens if you test our mice with your reagents" must have been framed. Given the state of knowledge of immune regulation in 1985 (or in 1988) any question raised or hypothesis stated required at least one specificity control. To make any sense at all out of immune manipulation of the transgenic mice, which carried an abnormally large number of copies of a pre-rearranged gene inserted in a variety of unnatural sites, required that comparisons be made with mice bearing a transgene of another (non-crossreacting) specificity. That would have been a minimum requirement for decent experimental design. Other mice expressing fewer copies of the transgene, for example, would have been desirable, but one must begin somewhere and there are practical considerations to take into account. Lacking the one basic control the discussion becomes pointless, and the arguments over technical issues a waste of time.

I believe the weakness in experimenta design, which is but one of many examples of the somewhat mindless application of the powerful techniques of molecular genetics and immunology, is more troublesome than the tempest in a teapot concerning the minutiae of test precision. With decent experimental design, the trivial questions would almost certainly not arise.

LEON T. ROSENBERG Department of Medical Microbiology, Stanford University School of Medicine, Stanford, California 94305-5404, USA

1. Maddox, J. Nature 333, 795-797 (1988).

2. Weaver, D. et al. Cell 45, 247-259 (1986)

\section{Forced dilemma to come in muscle contraction}

SIR-Malcolm Irving, in his interesting News and Views ${ }^{1}$ comment on the results of Kishino and Yanagida ${ }^{2}$, does not point out a major dilemma that will result for the understanding of muscle contraction if their preliminary estimate of the force per crossbridge at less than $1 \mathrm{pN}$ is confirmed.

Irving considers only the situation when the efficiency of energy conversion is in the region of $10 \%$, but the experimental values for muscle are much higher than this, in the region of $50-60 \%$ for $\mathrm{frog}^{3.4}$ and about $80 \%$ for tortoise ${ }^{5}$. The standard view of muscle contraction ${ }^{6}$ is that each crossbridge cycle is driven by the splitting of one ATP. Thus, even using the lowest estimate of muscle efficiency, the work done by a single crossbridge in one cycle averages $50 \%$ of the free energy of splitting one ATP molecule, that is, at least $43 \times 10^{-21} \mathrm{~J}$. From measurements of the force changes produced by length steps ${ }^{?}$ we know that the working stroke of a crossbridge is no more than $15 \mathrm{~nm}$. If follows that the average force produced by a crossbridge during shortening must be at least $3 \mathrm{pN}$, and presumably during isometric contraction it will be higher.

If it turns out from direct measurements that the force per crossbridge is indeed less than $1 \mathrm{pN}$ it will be necessary to suppose that one ATP molecule provides, on average, the energy for not one but several crossbridge cycles. This would require the myosin molecules to undergo a much more complex sequence of changes than anything now envisaged.

Department of Physiology,

$$
\text { R. C. Woledge }
$$

University College,

London WC1E 6BT, UK

1. Irving. M. Nature 334, 11 (1988)

. Kishino, A. \& Yanagida, T. Nature 328, 74-76 (1988)

3. Kushmerick. M.J. \& Davies, R.E. Proc. R. Soc. B174, 315$353(1969)$.

4. Hill, A.V Proc R. Soc, B126, 136-195 (1938)

5. Woledge, R.C. J. Physiol., Lond. 197, 685-707 (1968)

6. Huxley, A.F. Reflections on Muscle (Liverpool University Press. Liverpool, 1980).

7. Ford. L.E., Huxley, A.F. \& Simmons, R.M. J. Physiol., Lond. 311, 219-249 (1977) 